\title{
A study of depression among patients of substance use disorder
}

Pradhan SN', Sharma SC ${ }^{2}$, Shrestha $\mathrm{MR}^{3}$, Shrestha $\mathrm{S}^{4}$

${ }^{1}$ Associate Professor, ${ }^{2}$ Assistant Professor, Department of Psychiatry, Kathmandu Medical College Teaching Hospital, ${ }^{3}$ Associate Professor, Department of Psychiatry, National Academy of Medical Sciences, ${ }^{4}$ Intern, Department of Psychiatry, Kathmandu Medical College Teaching Hospital, Kathmandu, Nepal.

\section{Abstract}

Background: Depressive disorder is frequently found as a comorbidity among patients with substance abuse. Most of the time it is reported as underdiagnosed and a majority of patients go untreated. Many studies have indicated that comorbid depressive symptoms play a major role in the prognosis of substance use disorder and the relapse has been found to be greater in patients who have a comorbid depression. The present study seeks to determine the comorbidity of depression in cases with substance abuse and their sociodemographic characteristics.

Objective: The current study is aimed to determine the relationship between various drug abusing patterns and comorbidity of depression with substance use disorders.

Methods: This was a cross-sectional study. The study was carried out in 42 patients, who were consecutively admitted in psychiatric ward of Kathmandu Medical College Teaching Hospital and Punarjeevan Hospital with the diagnosis of mental and behavioural disorder due to use of psychoactive substances, according to ICD-10. The study was carried out from $1^{\text {st }}$ January 2010 to $30^{\text {th }}$ December 2010. All patients were rated using Hamilton Depression Rating Scale.

Results: Among all subjects, 31 (73.8\%) were found to be suffering from Depression among which 19 (45.2\%) had mild to moderate depression and $12(28.6 \%)$ had severe depression. Depression was seen among $80 \%$ of unemployed subjects, followed by $75 \%$ employed subjects and $68.8 \%$ students.

In method of drug intake, 21 (50\%) subjects used oral drugs, 12 (28.6\%) subjects used intravenous route and 5 (11.9\%) subjects used inhalational drugs. All patients using intravenous drugs were found to have depression.

Among drugs abused, 22 (52.4\%) patients used multiple substances like alcohol and cannabis, 11 (26.2\%) patients used Heroin, 6 (14.3\%) patients used drugs like Diazepam, Dextropropoxyphene, Nitrazepam and Promethazine, followed by $3(7.1 \%)$ patients using Buprenorphine. Depression was found in 6 (54.54\%) out of 11 subjects who used Heroin followed by 19 (86.63\%) out of 22 subjects who were dependent on alcohol, cannabis and other substances.

Conclusion: The result showed strong correlation between depressive symptoms and substance abuse, which draws attention to the need of taking into consideration the comorbidity and its management. Clinicians should routinely assess for depression in patients with substance abuse disorders.

Key words: Depression, ICD-10, substance use disorders.

\section{INTRODUCTION}

Drug abuse is becoming one of the major problems worldwide, affecting the youngsters, leading to depressive symptoms in between. A person who is suffering from depression may feel hopeless, lonely and distractable and gradually plunges into drug abuse and

Address for correspondence

Dr. Sudarshan N. Pradhan

Associate Professor, Department of Psychiatry

Kathmandu Medical College Teaching Hospital, Kathmandu, Nepal

Email: drsudar@yahoo.com vice versa. This two way relation is a serious matter of concern for the patient, their families, health services and society.

Patient with substance use disorder having depression run a higher risk of delayed diagnosis ${ }^{1}$, more severe psychopathological symptoms ${ }^{2}$, less compliance with treatment ${ }^{3}$, poorer effects of treatment ${ }^{4}$, more impairment of social functioning ${ }^{5}$, increased admissions to emergency department ${ }^{6}$, higher prevalence of physical comorbidity ${ }^{7}$, suicidal ideation ${ }^{8}$. They are often unemployed $^{9}$, homeless ${ }^{10}$, they are also involved in 
violent episodes ${ }^{11}$, or criminal activities ${ }^{12}$, and indulged in alcohol dependence ${ }^{13}$.

Epidemiological studies from different countries have shown a high prevalence of comorbid alcohol or other drug disorders. Epidemiologic Catchment Area Programme in the USA shows $53 \%$ of drug abusers had a mental disorder. ${ }^{14}$ The most common disorders were severe depression ${ }^{15,16}$. In a Canadian study, prevalence of major depressive disorder is three time higher in people with substance dependence than in the general population ${ }^{17}$.

A special precaution is required in substance use disorder, where comorbidity of mental disorder is likely to evolve. Most people with substance use disorder have mental disorders, and often do not receive any appropriate treatment. Most of the treatment centres treat for substance use disorders, however, they miss the comorbid mental disorder, which subsequently relapse after some time, affecting the patient, family members and society.

The objective of this study is to identify depression among patients with substance abuse disorders.

\section{METHODS}

The current study is aimed to determine the relationship between various drug abuse patterns and comorbidity of depression. The study was carried out in the patients, who were consecutively admitted in the psychiatric ward of Kathmandu Medical College Teaching Hospital and Punarjeevan Hospital with the diagnosis of mental and behavioural disorder due to use of psychoactive substances, according to ICD-10 18 . The study was carried out from $1^{\text {st }}$ January 2010 to $30^{\text {th }}$ December 2010. Informed consent of all the cases was taken. All patients were rated using Hamilton Depression Rating Scale $(\text { HDRS })^{19}$. The duration of substance intake as well as other variables was collected using a self designed semistructured proforma. All collected data was entered in the Statistical Package for Social Sciences 10.0 for windows.

\section{RESULT}

Total number of patients was 42. The variables compared were age, mode of drug abuse, type of drug used and occupation of the subjects and are shown in table 1.

A total of 31 (73.8\%) cases were found to be suffering from Depression, in which 19 (45.2\%) had mild to moderate depression and 12 (28.6\%) had severe depression.

Table 1: Prevalence and severity of depression and sociodemographic characteristics

\begin{tabular}{|c|c|c|c|c|}
\hline \multirow[b]{2}{*}{ Age } & \multicolumn{3}{|c|}{ HDRS } & \multirow[b]{2}{*}{ Total } \\
\hline & $\begin{array}{c}<7 \text { (Normal) } \\
\text { Number of subjects } \\
\text { (percentage) }\end{array}$ & $\begin{array}{l}\text { 7-20 (Mild to Moderate } \\
\text { Depression) } \\
\text { Number of subjects } \\
\text { (percentage) }\end{array}$ & $\begin{array}{c}>20 \text { (Severe } \\
\text { Depression) } \\
\text { Number of subjects } \\
\text { (percentage) }\end{array}$ & \\
\hline $11-20$ yrs & $4(9.5 \%)$ & $3(7.1 \%)$ & $1(2.4 \%)$ & $8(19.0 \%)$ \\
\hline $21-30$ yrs & $6(14.3 \%)$ & $13(31.0 \%)$ & $7(16.7 \%)$ & $26(61.9 \%)$ \\
\hline $31-40$ yrs & $1(2.4 \%)$ & $2(4.8 \%)$ & $4(9.5 \%)$ & 7 (16.7 \%) \\
\hline$>41 \mathrm{yrs}$ & $0(0 \%)$ & $1(2.4 \%)$ & $0(0 \%)$ & $1(2.4 \%)$ \\
\hline \multicolumn{5}{|l|}{ Method of Drug Intake: } \\
\hline IV user & $0(0 \%)$ & $7(16.7 \%)$ & $5(11.9 \%)$ & $12(28.6 \%)$ \\
\hline Inhalation & $3(7.1 \%)$ & $1(2.4 \%)$ & $1(2.4 \%)$ & $5(11.9 \%)$ \\
\hline Oral Drug Abuse & $7(16.7 \%)$ & $10(23.8 \%)$ & $4(9.5 \%)$ & $21(50.0 \%)$ \\
\hline $\begin{array}{l}\text { Other (Alcohol/ Cannabis } \\
\text { dependence) }\end{array}$ & $1(2.4 \%)$ & $1(2.4 \%)$ & $2(4.8 \%)$ & $4(9.5 \%)$ \\
\hline \multicolumn{5}{|l|}{ Drug Used: } \\
\hline Heroin & $5(11.9 \%)$ & $3(7.1 \%)$ & $3(7.1 \%)$ & $11(26.2 \%)$ \\
\hline Buprenorphine & $1(2.4 \%)$ & $0(0 \%)$ & $2(4.8 \%)$ & $3(7.1 \%)$ \\
\hline $\begin{array}{l}\text { Diazepam, Proxyvon, } \\
\text { Nitrazepam, Promethazine }\end{array}$ & $2(4.8 \%)$ & $2(4.8 \%)$ & $2(4.8 \%)$ & $6(14.3 \%)$ \\
\hline Others & $3(7.1 \%)$ & $14(33.3 \%)$ & $5(11.9 \%)$ & $22(52.4 \%)$ \\
\hline \multicolumn{5}{|l|}{ Occupation: } \\
\hline Employed & $2(4.8 \%)$ & $1(2.4 \%)$ & $3(7.1 \%)$ & $6(14.3 \%)$ \\
\hline Unemployed & $4(9.5 \%)$ & $11(26.2 \%)$ & $5(11.9 \%)$ & $20(47.6 \%)$ \\
\hline Student & $5(11.9 \%)$ & $7(16.7 \%)$ & $4(9.5 \%)$ & $16(38.1 \%)$ \\
\hline Total & $11(26.2 \%)$ & 19 (45.2 \%) & $12(28.6 \%)$ & $42(100.0 \%)$ \\
\hline
\end{tabular}


Eight patients (19\%) were in the age group 11-20years, 26 (61.9\%) were in the age group $21-30$ years, seven (16.7\%) were in age group 31-40 years and one patient (2.4\%) was above 41 years of age. Out of the eight patients of 11-20 years of age, four (50\%) had depression. Twenty patients (76.9\%) out of 26 patients from the age group 21-30 years had depression. Depression was seen in six (85.7\%) patients of age $31-40$ years.

Twenty (47.6\%) subjects were unemployed, followed by 16 (38.1\%) were students, 6 (14.3\%) employed. Among the 20 unemployed patients, $16(80 \%)$ had depression. Four out of six (66.6\%) employed subjects and 11 (68.8\%) out of 16 students had depression.

In method of drug intake, 21 (50\%) subjects used multiple drugs, $12(28.6 \%)$ subjects used intravenous route and 5 (11.9\%) subjects used inhalational drugs. All patients using intravenous drugs were found to have depression. Among patients taking drugs orally, depression was found in 6 (54.54\%) out of 11 subjects who used Heroin followed by 19 (86.63\%) out of 22 subjects who were dependent on alcohol, cannabis and other substances.

\section{DISCUSSION}

The present study showed that $73.8 \%$ patients with substance use disorder were suffering from depression. The results are consistent with findings of other researches. In a study done in Latin America, 58.4\% of illicit drug users had depression ${ }^{20}$. Another study ${ }^{21}$ showed that depression was present in $81.4 \%$. A study conducted with HIV-infected individuals who used illicit drugs, showed that $69.0 \%$ of the patients obtained scores suggestive of depression ${ }^{22}$. The comorbidity of depression with substance use disorder as found in our study also indicates that depression is a major comorbidity among patients with substance use disorder. As the person indulges in substance

\section{REFERENCES}

1. Albanese MJ, Clodfelter RC Jr, Pardo TB, Ghaemi $\mathrm{SN}$ : Underdiagnosis of bipolar disorder in men with substance use disorder. J Psychiatr Pract. 2006; 12:124-127.

2. Ringen PA, Melle I, Birkenaes AB, Engh JA, Faerden A, Vaskinn A, et al. The level of illicit drug use is related to symptoms and premorbid functioning in severe mental illness. Acta Psychiatr Scand. 2008;118:297-304.

3. Verheul R, Van den BW, Hartgers C. Personality disorders predict relapse in alcoholic patients. Addict Behav. 1998;23:869-882. use, personality factors like strange behaviour, social disinhibition and other type of psychotic symptoms come to the front whereas depression goes in the background and is underdiagnosed and undertreated.

In our study, substance abuse was found to be highest in age group of 21-30yrs (61.9\%), which shows that younger people are more vulnerable to develop substance abuse due to higher level of frustration, stressful life, keen competition among youngsters, which is consistent with the findings of a study conducted earlier in patients with alcohol abuse ${ }^{13}$.

The current study has revealed that majority of patients use oral form of various drugs as they find it easier in comparison to other methods such as intravenous use.

Heroin was consumed by $26.2 \%$. Heroin users usually show depressive symptoms as well as engagement in risk taking behaviours such as crime and theft and have poor physical health ${ }^{23,24}$.

The current study shows preponderance of substance use in unemployed subjects and students, which shows the gravity of unemployment in the country and disciplinary problems in school. This draws greater attention to the need for creating employment opportunities and implementing strict disciplinary rules in schools along with education among youths regarding harmful effect of substance abuse.

\section{CONCLUSION}

The result obtained shows the presence of depressive symptoms among patients with substance use disorder, which draws the attention to the need for adequate management of depressive symptoms in patients with substance use. Clinicians should routinely assess for depression in patients with substance use disorders.

4. Torrens M, Fonseca F, Mateu G, Farre M. Efficacy of antidepressants in substance use disorders with and without comorbid depression. A systematic review and meta-analysis. Drug Alcohol Depend. 2005;78:1-22.

5. Mazza M, Mandelli L, Di NM, Harnic D, Catalano $V$, Tedeschi $D$, et al. Clinical features, response to treatment and functional outcome of bipolar disorder patient with and without co-occurring substance use disorder:1-year follow-up. J Affect Diord. 2009;115:27-35.

6. Curran GM, Sullivan G, Williams K, Han X, Collins K, Keys J, et al. Emergency department use of persons 
with comorbid psychiatric and substance abuse disorders. Ann Emerg Med. 2003;41:659-667.

7. Rosenberg SD, Drake RE, Brunette MF, Wolford GL, Marsh BJ. Hepatitis C virus and HIV co-infection in people with severe mental illness and substance use disorders. AIDS. 2005;19(Suppl-33).

8. Cottler LB, Campbell W, Krishna VA, CunnighamWilliam RM, Abdallah AB. Predictors of high rates of suicidal idelation among drug users. J Nerv Ment Dis. 2005;193:431-437.

9. Fergusson DM, Horwood LJ, Lynskey MT. The effects of unemployment on psychiatric illness during young adulthood. Psychol Med. 1997;27:371-381.

10. Caton $C L$, Shrout PE, Eagle PF, Opler LA, Felix A, Dominguez B. Risk factors for homelessness among schizophrenic men: a case control study. Am J Public Health. 1994;84:265-270.

11. Elbogen EB, Johnson SC. The intricate link between violence and mental disorder: from the National Epidermitologic Survey on Alcohol and Related Conditions. Arch Gen Psychiatr. 2009;66:152-161.

12. Goldstein BI, Levitt AJ. The specific burden of comorbid anxiety disorders and of substance use disorders in bipolar I disorder. Bipolar Disord. 2008;10:67-78.

13. Pradhan SN, Adhikary SR, Sharma SC. A prospective study of comorbidity of alcohol and depression. Kathmandu Univ Med J. 2008;6(23):340-345

14. Register DA, Farmer ME, Rae DS, Locke BZ, Keith SJ, Judd LL, et al. Comorbidity of mental disorders with alcohol and other drug abuse. Results from the Epidemiologic Catchment Area (ECA) Study. JAMA. 1990;264:2511-2518.

15. Kessler RC, Nelson CB, McGonagle KA, Edlund MJ, Frank RG, Leaf PJ. The epidemiology of co-occurring addictive and mental disorders: implications for prevention and service utilization. AM J Orthopsychiatry. 1996;66:17-31
16. Kessler RC, Crum RM, Warner LA, Nelson CB, Schulenberg J, Anthony JC. Lifetime co-occurrence of DSM-III-R alcohol abuse and dependence with other psychiatric disorders in the National Comorbidity Survey. Arch Gen Psychiatry. 1997,54:313-321.

17. Currie SR, Patten SB, Williams JV, Wang J, Beck CA, El-Guebaly $\mathrm{N}$, et al. Comorbidity of major depression with substance use disorders. Can J Psychiatry. 2005;50:660-666.

18. World Health Organization. The ICD-10 Classification of Mental and Behavioral Disorders: Diagnostic Criteria for Research: World Health Organization; 1993.

19. Hamilton M.A rating scale for depression. J Neurol Neurosurg Psychiatry. 1960;23:56-73.

20. Ferigolo M, Stein AT, Fuchs FD, Barros HMT. Influence of depression and early adverse experiences on illicit drug dependence: a case control study . Rev Bras Psiquiatr. 2009;31(2):106-13.

21. Lemstra $M$, Rogers $M$, Thompson $A$, Moraros J, Buckingham R. Risk indicators of Depressive symptomatology Among Injection Drug Users and Increased HIV Risk Behavior. Can J Psychiatry. 2011;56(6);358-366.

22. Pirraglia PA, Bishop D, Herman DS, Trisvan E, Lopez RA, Torgersen CS, et al. Caregiver Burden and depression among informal caregivers HIV-infected individuals. J Gen Intern Med. 2005;20:510-4.

23. Conner KR, Pirquart M, Duberstain PR. Meta analysis of depression and substance misuse and impairment among intravenous drug users(IDUs). Addiction. 2008;103:524-34.

24. Darke S, Ross J. The use of antidepressants among injecting drug users in Sydney, Australia. Addiction. 2000;95:407-17. 